\title{
An application of data envelopment analysis for measuring the relative efficiency in banking industry
}

\author{
Mehdi Soltanifar $^{\mathbf{a}^{*}}$ and Fereshteh Farhadi ${ }^{\mathrm{b}}$
}

${ }^{a}$ Assistant Professor, Department of Applied Mathematics, Semnan Branch, Islamic Azad University, Semnan, Iran

${ }^{b}$ M.A Student, Department of Industrial Management, Semnan Branch, Islamic Azad University, Semnan, Iran

\section{CH R O N I C L E}

\section{Article history:}

Received 5 January 2014

Received in revised format

8 March 2014

Accepted 11 March 2014

Available online

12 March 2014

Keywords:

Data envelopment analysis

$D E A$

Banking industry

Semnan Industry

\section{A B S T R A C T}

Measuring the relative efficiency of banking industry has been a popular subject among both practitioners and academicians. Data envelopment analysis (DEA) has been widely applied for different purposes. This paper presents an empirical investigation to measure the relative efficiency of various banks located in province of Semnan, Iran. The proposed study uses DEA method to rank all units and using Anderson and Peterson method (1993) [Andersen, P., \& Petersen, N. C. (1993). A procedure for ranking efficient units in data envelopment analysis. Management Science, 39, 1261-1264], we provide some super efficiency for inefficient units. The study also provides reference numbers for inefficient units and gives some target values for all inefficient units.

\section{Introduction}

During the past few years, there have been tremendous efforts on applying different methods for measuring the relative performance of business units such as activity based cost method, theory of constraints, balanced scorecard, etc. Data envelopment analysis (DEA) is one of the most popular techniques among both practitioners and scientists (Kuah et al., 2010; Cooper et al., 2011). The method has been applied for measuring technology (Khouja, 1995), measuring the performance of airports (Roghanian \& Foroughi, 2010), supplier selection (Levary, 2008; Azar et al., 2011; Nourbakhsh et al., 2013) and heath care (Ghotbuee et al., 2012; Khani et al., 2012). Charnes et al. $(1978,1985,1990)$ are believed to be the first who introduced the idea of measuring non-financial units based on various inputs/outputs. There are various types of DEA methods including constant return to scale, variable return to scale, input/output oriented, etc.

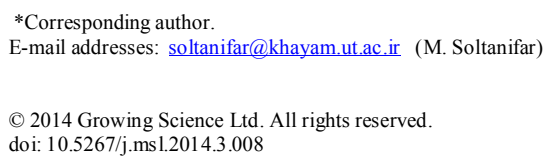


DEA has been extensively implemented in banking industry for many years (Camanho \& Dyson, 2005; Chen et al., 2005; Sowlati et al., 2005; Edirisinghe \& Zhang, 2007). Farkousha et al. (2011) proposed a method to utilize balanced score card (BSC) as a tool for designing performance evaluation indices in banking industry. Khaki et al. (2012) proposed a BSC-DEA technique to rank various decision making units. They considered various financial criteria such as profit-margin, return on assets along with non-financial criteria such as customer satisfaction, advanced services, employee skills to compare the performance of different banks.

Azarbad et al. (2011) presented a BSC-DEA based model to identify strengths, weaknesses, opportunities and threats of a firm. They considered there were various uncertainties associated with all input/output parameters and applied fuzzy numbers to handle the uncertainties. They also considered a real-world case study of banking industry where four major banks were possible candidates of a partnership and implemented the proposed model for the case study. The results have disclosed some of the issues such as weakness of electronic banking, services and resource allocation as part of their infrastructure problems.

Wanke and Barros (2014) measured efficiency in Brazilian banking using a two-stage process where in the first stage, the number of branches and employees were used to attain a certain level of administrative and personnel expenses per year. In the productive efficiency stage, these expenses permitted the consecution of two important net outputs including equity and permanent assets. They applied the network-DEA centralized efficiency model to optimize both stages, simultaneously. They reported that Brazilian banks were heterogeneous, with some concentrating on cost efficiency and others on productive efficiency. In addition, cost efficiency was described by marketing and administration (M\&A) as well as size, while productive efficiency was described by M\&A and public status. Liu et al. (2009) applied DEA technique to measure the relative efficiencies on a bank in Taiwan and studied the performance and productivity changes when banks implement financial electronic data interchange. They included 18 branches of the performance for implementation of financial electronic data interchange of the overall efficiency, pure technical efficiency, scale efficiency, analysis of reference groups and the potential to improve the value of analysis for different branch performance assessments. The empirical results shown that case bank could adopt the DEA evaluation model as references to upgrade the overall operating performance effectively for creating competitive advantages. Wang et al. (2014) utilized network DEA method to evaluate efficiencies of the Chinese commercial banks.

\section{The proposed study}

In this paper, we present an output oriented data envelopment analysis to measure the relative efficiency of an Iranian private bank named Bank Mehr located in province of Semnan, Iran. The study also uses Andersen and Petersen (1993) for supper efficiency measurement and provides some additional information for ranking efficient banks.

\subsection{The DEA method}

The constant return to scale DEA (CCR) was first introduced by Charnes, et al. $(1978,1994)$ for measuring the relative efficiency of decision making units (DMU). This method allows us to understand how a given DMU works whenever a production function is available. However, in many cases obtaining an analytical form for this function is not available. Therefore, we may form a set of production feasibility, which constituts of various principles such as fixed-scale efficiency, convexity and feasibility as follows,

$$
T_{C}=\left\{(X, Y) \mid X \geq \sum_{j=1}^{n} \lambda_{j} X_{j}, Y \leq \sum_{j=1}^{n} \lambda_{j} Y_{j}, \lambda_{j} \geq 0, j=1, \cdots n\right\},
$$


where $X$ and $Y$ state the input and output vectors, respectively. The CCR production feasibility set border presents the relative efficiency where any off-border DMU is stated as inefficient. The CCR model can be computed in two kinds of either input or output oriented. The input CCR aims to decrease the maximum input level with a ratio of $\theta$ so that, at least, the same output is produced, i.e.:

$\min \theta$

subject to

$\theta X_{p}-\sum_{j=1}^{n} \lambda_{j} X_{i j} \geq 0$

$\sum_{j=1}^{n} \lambda_{j} Y_{r j} \geq Y_{r p}$

$\lambda_{j} \geq 0, \quad j=1, \cdots, n$.

Model (2) is an envelopment form of input CCR where $\theta$ is the relative efficiency of the DMU and it is possible to show that the optimal value of $\theta, \theta^{*}$, is located between zero and one. In an input oriented DEA model, once the efficiency of a DMU unit, $D M U_{p}$, lies in case of inefficiency, one may directs it towards the border to change it efficient. In the case of the output oriented DEA model, the primary objective is to maximize the output level, $\varphi$, by using the same amount of input. The model can be formulated as follows,

$\min \varphi$

subject to

$\sum_{j=1}^{n} \lambda_{j} X_{i j} \leq X_{i p}$,

$\sum_{j=1}^{n} \lambda_{j} Y_{j} \geq \varphi Y_{i p}$,

$\lambda_{j} \geq 0, \quad j=1, \cdots, n$.

There are literally various types of DEA method and the BCC output oriented DEA model is used in this paper, which is as follows,

$\max z=\theta-\varepsilon\left(\sum_{r=1}^{s} S_{r}^{+}+\sum_{i=1}^{m} S_{i}^{-}\right)$

subject to

$\sum_{j=1}^{n} \lambda_{j} y_{r j}-S_{r}^{+}=\theta y_{r 0} \quad(r=1, \cdots, s),(j=1, \cdots, n)$

$\sum_{j=1}^{n} \lambda_{j} x_{r j}+S_{r}^{-}=x_{r 0} \quad(i=1, \cdots, m)$

$\sum_{j=1}^{n} \lambda_{j}=1$

$\lambda_{j}, s_{i}^{-}, s_{r}^{+} \geq 0, \theta$ free in sign

The results of the DEA implementation normally lead us to have more than one efficient unit and it is possible to use the method developed by Andersen and Petersen (1993) to rank efficient units, separately. In order to convert the inefficient units to efficient ones, we need to use phase III of this method, which gives better image of the whole system as follows, 
$\min W$

subject to

$$
\begin{aligned}
& \sum_{j \in R} \lambda_{j} x_{i j}+\delta_{i}^{-} x_{i o}=x_{i o}, i=1, \ldots, m, \\
& \sum_{j \in R} \lambda_{j} y_{r j}-\delta_{r}^{+} y_{r o}=\varphi^{*} y_{r o}, \quad r=1, \ldots, s, \\
& \sum_{j \in R} \lambda_{j}=1, \quad 0 \leq \delta_{i}^{-} \leq p, \quad i=1, \ldots, m, \quad 0 \leq \delta_{r}^{+} \leq q, r=1, \ldots, s, \quad p \leq W, q \leq W, \\
& \lambda_{j} \geq 0, j=1, \ldots, n .
\end{aligned}
$$

where $\delta_{i}^{-}$and $\delta_{i}^{+}$associated with dual variable and both are limited within bounds $0 \leq \delta_{i}^{-} \leq p$ and $0 \leq \delta_{r}^{+} \leq q$. The problem uses the following method for converting inefficient unit into efficient ones.

$\hat{x}_{i o}=x_{i o}\left(1-\delta_{i}^{-}\right), i=1, \ldots, m$,

$\hat{y}_{r o}=y_{r o}\left(\varphi^{*}+\delta_{r}^{+}\right), \quad r=1, \ldots, s$,

The proposed study of this paper has four levels. In the first level, the study determines the input/output parameters. In the second stage, BCC method is applied to rank all banks, and the efficient units are ranked in the third stage using Anderson and Peterson method. Finally, in fourth stage, we use model (4) to bring inefficient method close to efficient frontier. Table 1 shows input/output of the proposed study.

\section{Table 1}

The summary of input/output

\begin{tabular}{ccccc}
\hline \multicolumn{2}{c}{ Input } & & & Output \\
\hline Branch & Equipment & Employee & Profit & Resources absorbed \\
\hline 1 & 150 & 68 & 3658.6 & 426492473 \\
2 & 199 & 96 & 2613.7 & 778321941 \\
3 & 152 & 85 & 3512.92 & 692635565.1 \\
4 & 190 & 129 & 3030.66 & 947961015 \\
5 & 155 & 88 & 6376.8 & 454534779 \\
6 & 202 & 99 & 6009.19 & 534347212.9 \\
7 & 114 & 62 & 0 & 452380978 \\
8 & 233 & 109 & 4255.25 & 787695134.3 \\
9 & 153 & 78 & 2508.94 & 5343472113 \\
10 & 123 & 63.5 & 6990.5 & 425257233 \\
11 & 175 & 52 & 3135.72 & 196936618 \\
& 119 & 957484364 & \\
\hline
\end{tabular}

As we can observe from the results of Table 1, the proposed study considers two inputs, equipment and employee, and two outputs, profit and resources absorbed, for 12 different banks located in province of Semnan, Iran.

\section{The results}

In this section, we present details of our implementation of DEA method for 12 branches of bank.

\begin{tabular}{|c|c|c|}
\hline Branch & Efficiency & Dual variable \\
\hline 1 & 0.8281 & 965.75 \\
\hline 2 & 0.8719 & 804.93 \\
\hline 3 & 1 & 0 \\
\hline 4 & 1 & 0 \\
\hline 5 & 1 & 0 \\
\hline 6 & 0.6799 & 42.6 \\
\hline 7 & 1 & 0 \\
\hline 8 & 0.8084 & 3285.7 \\
\hline 9 & 0.8082 & 11.37 \\
\hline 10 & 0.909 & 30.004 \\
\hline 11 & 1 & 0 \\
\hline 12 & 1 & 0 \\
\hline
\end{tabular}
Table 2 shows details of our proposed model.

Table 2

The summary of BSC method 
As we can observe from the results of Table 2, there are six units, which are efficient and the remaining six units are considered as inefficient units. The implementation of Anderson and Peterson are summarized in Table 3 as follows,

\section{Table 3}

The result of the implementation of supper efficiency using Anderson \& Peterson technique

\begin{tabular}{lcccccc}
\hline Unit number & 3 & 4 & 5 & 7 & 11 & 12 \\
\hline Rank & 2.79 & 3.01 & 2.81 & 2.76 & 7.82 & 2.8 \\
\hline
\end{tabular}

Next, we have to find an index to convert the inefficient units into an efficient one. Table 4 shows details of our findings.

Table 4

The summary of reference units along with their weights

\begin{tabular}{lllllll}
\hline Unit & 3 & 4 & 5 & 7 & 11 & 12 \\
\hline 1 & 0.2609 & 0 & 0 & 0.7391 & 0 & 0 \\
2 & 0.6765 & 0 & 0 & 0 & 0 & 0.3235 \\
3 & 1 & 0 & 0 & 0 & 0 & 0 \\
4 & 0 & 1 & 0 & 0 & 0 & 0 \\
5 & 0 & 0 & 1 & 0 & 0 & 0.1592 \\
6 & 0 & 0 & 0.728 & 0.1129 & 0 & 0 \\
7 & 0 & 0.6934 & 0 & 0 & 0 & 0 \\
8 & 0 & 0 & 0.0678 & 0.6819 & 0 & 0.2494 \\
9 & 0 & 0 & 0 & 0 & 0 & 0 \\
10 & 0 & 0 & 0 & 0 & 1 & 0 \\
11 & 0 & 0 & 0 & 0 & 0 & 1 \\
12 & 0 & & & & & 0 \\
\hline
\end{tabular}

According to Table 4, unit 1 can become efficient through two units of 3 and 7 and the second bank can also become efficient through unit 3 and 12. Based on the information, we may provide efficient amount of resources and Table 5 shows details of our findings.

Table 5

The summary of efficient amount of inputs/outputs

\begin{tabular}{|c|c|c|c|c|}
\hline \multirow[b]{2}{*}{ Branch } & \multicolumn{2}{|c|}{ Input } & \multicolumn{2}{|c|}{ Output } \\
\hline & Equipment & Employee & Profit & Resources absorbed \\
\hline 1 & 123.91 & 68 & 5357.989 & 515056087.7 \\
\hline 2 & 171.25 & 96 & 3390.885 & 773821941.2 \\
\hline 3 & 152 & 85 & 3512.92 & 692635565.1 \\
\hline 4 & 190 & 129 & 3030.66 & 947961015 \\
\hline 5 & 155 & 88 & 7376.8 & 454534779 \\
\hline 6 & 159.37 & 90 & 6547.392 & 534347212.9 \\
\hline 7 & 114 & 62 & 6009.19 & 452380978 \\
\hline 8 & 169.3 & 108.9171 & 2870.696 & 787695134.3 \\
\hline 9 & 141.13 & 78 & 5386.587 & 578486086.8 \\
\hline 10 & 122.5 & 63.5 & 2508.94 & 425257233 \\
\hline 11 & 175 & 52 & 6990.5 & 196936618 \\
\hline 12 & 211.5 & 119 & 3135.72 & 957484364 \\
\hline
\end{tabular}

\section{Conclusion}

This paper has presented an empirical investigation to measure the relative efficiency of various banks located in province of Semnan, Iran. The proposed study has applied DEA method to rank all units and using Anderson and Peterson method, we have provided some super efficiency for inefficient units. We have also provided reference numbers for inefficient units and provided target values for all inefficient units.

\section{References}

Andersen, P., \& Petersen, N. C. (1993). A procedure for ranking efficient units in data envelopment analysis. Management Science, 39, 1261-1264. 
Azarbad, M., Ekhtiari, M., Sarfaraza, A \& Abdi, F. (2011). A framework to select commercial bank partner using fuzzy BSC-DEA method. Management Science Letters, 1(4), 467-480.

Azar, A., Olfat, L., Khosravani, F., \& Jalali, R. (2011). A BSC method for supplier selection strategy using TOPSIS and VIKOR: A case study of part maker industry. Management Science Letters, 1(4), 559-568.

Camanho, A. S., \& Dyson, R. G. (2005). Cost efficiency measurement with price uncertainty: a DEA application to bank branch assessments. European Journal of Operational Research, 161(2), 432-446.

Charnes, A., Cooper, W.W., \& Rhodes, E. (1978). Measuring the efficiency of decision making units. European Journal of Operational Research, 2(6), 429-444.

Charnes, A., Cooper, W.W., Golany, B., Seiford, L.M., \& Stutz, J. (1985). Foundations of data envelopment analysis and Pareto-Koopmans empirical production functions. Journal of Econometrics, 30(1-2), 91-107.

Charnes, A., Cooper, W.W., Huang, Z.M., \& Sun, D.B. (1990). Polyhedral cone-ratio DEA models with an illustrative application to large commercial banks. Journal of Econometrics, 46(1-2), 73-91.

Chen, X., Skully, M., \& Brown, K. (2005). Banking efficiency in China: Application of DEA to pre-and post-deregulation eras: 1993-2000. China Economic Review, 16(3), 229-245.

Cooper, W.W., Lawrence, M.S., \& Zhu, J. (2011). Handbook on data envelopment analysis. International Series in Operations Research \& Management Science, Springer, 164, 1-40.

Edirisinghe, N. C. P., \& Zhang, X. (2007). Generalized DEA model of fundamental analysis and its application to portfolio optimization. Journal of Banking \& Finance, 31(11), 3311-3335.

Farkousha, S., Najafi, E \& Aryanezhad, M. (2011). A BSC-DEA approach to measure the relative efficiency of service industry: A case study of banking sector. International Journal of Industrial Engineering Computations, 2(2), 273-282.

Ghotbuee, A., Hemati, M \& Fateminezhad, R. (2012). An empirical study based on BSC-DEA to measure the relative efficiencies of different health care centers in province of Semnan, Iran. Management Science Letters, 2(7), 2643-2650.

Khaki, A., Najafi, S \& Rashidi, S. (2012). Improving efficiency of decision making units through BSCDEA technique. Management Science Letters, 2(1), 245-252.

Khani, F., Naderi, H., Zangeneh, M., \& Fazeli, E. (2012). Measuring the relative efficiency of Ilam hospitals using data envelopment analysis. Management Science Letters, 2(4), 1189-1194.

Khouja, M. (1995). The use of data envelopment analysis for technology selection. Computers and Industrial Engineering, 28(1), 123-132.

Kuah, C.T., Wong, K.Y., \& Behrouzi, F. (2010). A review on data envelopment analysis (DEA). Proc. of $4^{\text {th }}$ Asia International Conference on Mathematical/Analytical Modelling and Computer Simulation, 168-173.

Levary, R.R. (2008). Using the analytic hierarchy process to rank foreign suppliers based on supply risks. Computers and Industrial Engineering, 55(2), 535-542.

Liu, Z., Lin, F., \& Fang, L. P. (2009). A study of applying DEA to measure performance on bank implementing financial electronic data interchange. International Journal of Electronic Business Management, 7(4), 268-277.

Nourbakhsh, V., Ahmadi, A \& Mahootchi, M. (2013). Considering supply risk for supplier selection using an integrated framework of data envelopment analysis and neural networks. International Journal of Industrial Engineering Computations, 4(2), 273-284.

Roghanian, E., \& Foroughi, A. (2010). An empirical study of Iranian regional airports using robust data envelopment analysis. International Journal of Industrial Engineering Computations, 1(1), 65-72.

Sowlati, T., Paradi, J. C., \& Suld, C. (2005). Information systems project prioritization using data envelopment analysis. Mathematical and Computer Modelling, 41(11), 1279-1298.

Wanke, P., \& Barros, C. (2014). Two-stage DEA: An application to major Brazilian banks. Expert Systems with Applications, 41(5), 2337-2344.

Wang, K., Huang, W., Wu, J., \& Liu, Y. N. (2014). Efficiency measures of the Chinese commercial banking system using an additive two-stage DEA. Omega, 44, 5-20. 